This is the author's final, peer-reviewed manuscript as accepted for publication. The publisher-formatted version may be available through the publisher's web site or your institution's library.

\title{
The effect of advertisement choice on attention
}

Stephen C. Nettelhorst and Laura A. Brannon

\section{How to cite this manuscript}

If you make reference to this version of the manuscript, use the following information:

Nettelhorst, S. C., \& Brannon, L. A. (2012). The effect of advertisement choice on attention. Retrieved from http://krex.ksu.edu

\section{Published Version Information}

Citation: Nettelhorst, S. C., \& Brannon, L. A. (2012). The effect of advertisement choice on attention. Computers in Human Behavior, 28(2), 683-687.

Copyright: Copyright 2011 Elsevier Ltd.

Digital Object Identifier (DOI): doi:10.1016/j.chb.2011.11.015

Publisher's Link: http://www.sciencedirect.com/science/article/pii/S0747563211002597 
The Effect of Advertisement Choice on Attention

Stephen C. Nettelhorst and Laura A. Brannon

Kansas State University 


\begin{abstract}
The purpose of this study was to assess the effect of advertisement choice on individuals' subsequent attention towards the advertisement. Participants in this study decided which type of advertisement to watch or they were not given a choice. Results of the study showed that advertisement choice significantly influenced female participants' subsequent attention towards the advertisement but not males'. This effect suggests that this marketing technique should be used in specific situations to target women predominately. These include marketing products predominately or universally used by females or during shows which are viewed by a large number of females.
\end{abstract}

Keywords: advertisement choice; sex differences; attention; selective exposure. 


\section{Introduction}

Advertisers in various fields have mostly used existing methods from other mediums when trying to persuade some audience through the web. Like other media (e.g. television), internet advertising usually involves exposing an audience to a generic advertisement which may or may not draw any interest. This method of advertisement exposure does not take a personalized approach. With the increase use of the internet over the years, however, advertisers are using more personalized methods to persuade individuals. One example includes using previously seen websites as a basis for banner advertisement exposure. While these new techniques do improve the personalization of internet advertising, they still use some amount of guesswork to draw interest. It is only recently that certain websites (e.g. hulu.com) have allowed web users themselves to choose which advertisements to be exposed to. While this new methodology is a progression toward advertisement personalization, its influence on persuasion effects has not been examined.

When looking at traditional persuasion effects, Hovland, Janis, and Kelley [24] through their message-learning approach suggest that individuals go through four processes before persuasion takes place [33]. These processes in temporal order include attention, comprehension, yielding, and retention. Based on McGuire's [26] model, the attention, comprehension, and retention processes all influence the reception of any particular message while yielding is its own factor. When describing this model, McGuire states that the persuasion literature at his time was too focused on the yielding process itself compared to the other processes (e.g. attention) leading to attitude change. This critique seems to hold even to this day as the majority of research in the persuasion literature seems to focus on the effect of various factors such as message relevance [30,31,34], message strength/persuasiveness [19,23,34,35], 
and need for cognition $[6,7,36,43]$ have on persuasion (i.e. yielding) itself. However, this focus on the yielding process specifically does not mean that the attention process itself (and its relation to other processes) has been completely ignored.

Goodrich [21] examined how the location of a web banner advertisement, the type of banner advertisement, and the type of web page affected individuals' attention of the advertisement itself. Goodrich found that attention towards the advertisement was higher for pictorial banner advertisements than text based advertisements. Goodrich also found an interaction between advertisement location and the type of web page on attention where attention was higher on the right side of the web page than the left when the web page was image oriented. When linking the attention process to other persuasion constructs, Goodrich found that increased attention was positively related to aided recall of the advertisement and purchase intention. Similar relationships were found in in Chattopadhyay and Nedungadi [9]. In their examination of the persuasion process, Chattopadhyay and Nedungadi manipulated the likeability of the advertisement, the time of the attitude's measurement, and the amount of attention paid to the advertisement itself. Chattopadhyay and Nedungadi found that attitude towards the advertisement was affected by an interaction between amount of attention and time of attitude measurement. Specifically, the authors found attitudes to be higher with high amounts of attention when the attitude was measured immediately. When there was a week delay in measurement, however, attitudes were higher when there were low amounts of attention paid to the advertisement. Additionally, Chattopadhyay and Nedungadi found that higher amounts of attention led to higher amounts of brand cognitions but not cognitions toward the advertisement itself. In sum these studies seem to show that higher amounts of attention towards an advertisement can result in increases in other persuasion related outcomes as well. However, 
research on selective exposure suggests that individuals select and attend to specific bits of information which makes the attention-persuasion link more complex.

According to the notion of selective exposure, individuals typically choose to be exposed to information that is congruent with their existing opinions and/or attitudes when they are given the ability to choose what they are exposed to. This phenomenon is labeled confirmation bias [25] or congeniality bias $[14,15]$. The standard explanation for this phenomenon comes from Festinger's [17] theory of cognitive dissonance. Using this theory, many researchers believe that individuals selectively attend to information in order to protect and maintain their existing attitudes by avoiding information perceived to threaten those existing attitudes [22]. The selection of information that is consistent with a person's displayed behavior is more pronounced when the behavior is freely chosen than when it is forced on the individual $[11,20]$. Advertisement choice gives individuals the opportunity to selectively attend to a type of advertisement that they find more desirable, so it seems reasonable that one's attention would be influenced by this opportunity. The effect of advertisement choice should most directly influence the attentional process. Specifically, this study asks whether individuals who choose to watch an advertisement attend to the advertisement more than individuals who are not offered that choice.

Brehm [4] found that making a choice leads to more positive outcomes compared to when no choice is allowed. Individuals who were given a choice of products subsequently had more positive evaluations of the chosen product than individuals who were given a product without being given a choice. From an advertising standpoint, one way for an individual to show a more positive outcome is to pay more attention to the advertisement itself. Therefore, based upon Brehm's results, making a choice concerning which advertisement to be exposed to should 
increase one's subsequent attention towards it. In a related examination of choice, Freedman and Steinbruner [18] examined how perceived freedom (i.e. choice) over one's evaluation on some target affected participants' attitudes. Freedman and Steinbrunner found no significant difference in initial evaluation between the choice and no choice condition, however, attitude resistance to counterattitudinal information was significantly greater in the choice condition than the no choice condition. Although one might think that this study implies that choice of advertisement content will not affect individuals' subsequent attention, it should be noted that choice for Freedman and Steinbrunner concerned the evaluation of the target itself rather than choice of exposure. Thus despite the findings of Freedman and Steinbrunner, the possibility still remains that choice of advertisement content itself could influence individuals' attention towards the advertisement specifically.

Since these initial choice studies, more contemporary research in both advertising and non-advertising contexts has found personal choice to affect other attitudinal outcomes. In a test of perceived choice within an advertising context, Schlosser and Shavitt [37] manipulated whether or not participants would choose selective (i.e. different) information about a product after being exposed to the product on the company's website. Schlosser and Shavitt found that participants had significantly higher attitudes about the product when given a choice compared to no choice and that this effect was mediated by participants' positive attitudes about the product's company when given the choice. Additionally, Schlosser and Shavitt found greater attitude resistance to counterattitudinal information when participants chose specific product information compared to having no choice. However, Schlosser and Shavitt also found that such effects were eliminated if participants perceived choice to be a persuasion tactic by the company specifically. In interpreting their findings, Schlosser and Shavitt conclude, "the results of experiment 3 
suggest that calling attention to something as simple as choosing which message to receive can have positive effects on company and product judgments" (pg. 298). When generalizing these findings, however, two questions need to be raised. First, do these results generalize when the choice options concern different products rather than different qualities or aspects of the same product? Second, do these results generalize when the choice cannot be attributed to the company itself? In recent internet marketing contexts, the choice over advertisements is provided not by the products' respective companies but by the company providing the entertainment itself (e.g. hulu.com or youtube.com). Thus an unexplored question is whether or not individuals will be influenced by choosing an advertisement from different product options from a third party (i.e. company) provider. The purpose of this study is to address this specific question.

However, contrary to the notion that choice would increase cognitive and attitudinal outcomes, some research shows the opposite pattern [10]. Cho, Lee, and Tharp [10] showed that increasing the degree of forced exposure of banner advertisements actually increased participants' memory of the advertisement, the clickthrough rate of the advertisement, and attitudes toward the advertisement itself. However, it should be noted that Cho et al.'s manipulation concerned forced exposure to the advertisement itself (as opposed to voluntary exposure) rather than the content of the advertisement (forced exposure to a particular advertisement rather than a choice between advertisements). In Cho et al.'s study, participants had different options concerning how much of the actual advertisement they watched. In most experiments, exposure to advertisements is forced (as will be the case in this study).

When considering the possible effect of advertisement choice on viewers' attention, one variable that deserves exploration as a possible moderator is topic interest. The importance of 
this potential moderator stems from Ackerman and Gross' [1] study concerning the impact of choice on a hypothetical college marketing minor option. This study found that perceived desire and satisfaction for the marketing option were both significantly higher when participants were allowed to choose which classes to take within the marketing option compared to when those classes were decided for them. The study also found perceived desire to be significantly higher as the degree of choice increased when individuals were highly interested in the marketing option initially. Additionally, the authors of this study make an interesting analogy between their context and an consumer context by stating, "students' desire for choice in curricular offerings may be likened to consumer desire, which is a wish or yearning for particular products or services” (pg. 70). This same comparison has been made from Schwartz [38] who also suggested a high degree of overlap between choice within an educational context and choice within a consumer context. When one applies these evaluations to an online advertising context, two implications arise. The first implication, much like the implication from Schlosser and Shavitt [37], is that the choice of advertisements should lead to an increase in the amount of individual attention towards the advertisement itself. The second implication is that choice in consumer and advertising contexts on criterion variables (e.g. attention) should have a larger effect on individuals who are more interested in consumer and advertised products.

One example of a variable which reflects an individual difference in consumer and advertisement context is participant sex. Literatures from various fields have noted sex differences concerning attitudes and behavior in consumer and advertising contexts. Some research for example showed that males find shopping itself as a more undesirable activity than females $[2,12]$. Other research showed that males made quicker and more careless consumer decisions while spending less time shopping than females [8,27]. Regarding sex differences in 
the advertising literature, multiple studies have found greater advertising effects, both affectively and behaviorally, for women than men $[3,28,29]$. Additionally, Wolburg and Pokrywezynski [42] found that females rated web advertisements significantly higher in informativeness than males demonstrating that females value web advertisements more than males do. Given that multiple studies have noted significant sex differences concerning various aspects of consumer behavior, the tendency to be more influenced by an advertisement that is freely chosen over one where there is no choice is expected to be moderated by the viewer sex.

The present study assesses what impact choice of advertisement content and viewer sex have on individuals' attention to the advertisement. To address this question, a group of men and women were given a choice over which advertisement to watch and was compared to an independent group of men and women that watched the same advertisement without being given a choice of what to watch. Rather than varying the emphasis of the message concerning a specific product, the choice options for this study pertained to different products. In addition, this study could not be attributed to any particular company but a third party provider instead. Based on the results of both classic and more contemporary research concerning both the effect of choice and sex differences in consumer and advertising contexts, the following hypotheses were made:

H1: Both male and female viewers will attend to the advertisement more when they are given the choice of advertisement content than when they have no choice of advertisement content.

$\mathrm{H} 2$ : The effect of advertisement choice on attention towards the advertisement will be significantly greater for female viewers than for male viewers. 


\section{Method}

\subsection{Participants}

One hundred fifty-eight students from a large Midwestern university participated in this study. Eighty students (50.6\%) were female. One hundred thirty-nine students $(88.0 \%)$ were self-identified Caucasians. Students' average age was 19.16 years. All students were enrolled in an introductory psychology class at the time of participation, and students were compensated with credit for their participation.

\subsection{Materials}

In order to create a choice between different advertisement options, a pretest was conducted where participants' attitudes toward 28 different products were measured. A sample of 57 separate students from the same university participated in the pretest. The products ranged from a variety of consumer categories including various clothing, furniture, appliance, sporting equipment, and electronic items. Specific examples of products include shoes, recliners, microwaves, treadmills, and laptops. The purpose of the pretest was to find two specific products. The first product was a highly favorable product so that its inclusion as a choice option would be highly desirable. The second product was a slightly less favorable (but still favorable overall) product than the first. The inclusion of this product then would make the advertisement choice clear towards the first product but still somewhat difficult.

Three 9-point Likert items measured participants' general attitude, purchasing interest, and enjoyment of commercial watching for each product where higher values represent more favorable ratings for each variable. General attitude was measured by asking for participants' evaluation of each product using an extremely negative/extremely positive continuum.

Purchasing interest was measured by asking participants how interested they were in buying each 
item using a not interested/very interested continuum. Commercial enjoyment was measured by asking participants to rate the degree to which they enjoy watching commercials for each product using a low/high continuum. Results from the pretest showed that a MP3 player was rated highest for general attitude $[M=7.61, S D=1.67]$, purchase interest $[M=6.84, S D=2.60]$, and commercial enjoyment $[M=6.19, S D=2.67]$. Thus a MP3 player became the first choice option in the main study. To avoid any potential problem comparing products from different product categories, a slightly less favorable electronic product was used as the second choice option. Results from the pretest showed that a digital camera fit the role of the second option with consistent yet a slight decrease in general attitude $[M=6.96, S D=1.88]$, purchase interest $[M=$ $6.18, S D=2.87]$, and commercial enjoyment $[M=5.42, S D=2.78]$ compared to digital cameras. Thus the choice options for this study were a MP3 player and a digital camera.

Since a MP3 player was selected as the primary choice option, a MP3 advertisement was selected as the target advertisement. This advertisement was a 53 second commercial for a Zune MP3 player (a relatively unfamiliar product). The advertisement provides an overview of the MP3 player itself and the various functions it can perform. From the perspective of the Elaboration Likelihood Model [32], the advertisement relies on various central aspects (e.g. message strength) rather than any peripheral aspects (e.g. attractive endorser). This advertisement was embedded within two video clips whose purpose was to provide filler viewer material. These clips included either a videotaped musical performance or a Saturday Night Live skit. Two clips were used to increase generalizability of the materials in this study. This video was shown to participants within a video player using a blank webpage as a backdrop. Participants' sex was measured through an open-ended demographic question requiring participants to indicate their own sex. Attention towards the advertisement was measured using 
a 7-point Likert item. This item asked participants to rate the amount of attention they paid to the advertisement itself using a none/a lot continuum with higher ratings representing larger amounts of attention.

\subsection{Procedure}

After signing a writing consent form, participants were told that the purpose of the study was to assess how individuals respond to watching television content in an online format. Participants started the experiment by watching a video clip. This first clip contained either a choir performance or part of a Saturday Night Live Celebrity Jeopardy skit. After watching the first clip, rated the clip on a variety of dimensions (e.g. attitudes toward the video). Participants then were either immediately exposed to the advertisement itself or they were given the choice of advertisement type. Participants in the no choice condition were immediately exposed to the MP3 advertisement after completing the measures for the first video clip. In contrast, those in the advertisement choice condition were given the option to select an advertisement between two types of products (a MP3 player and a digital camera). If participants chose the MP3 advertisement, then they immediately viewed the MP3 advertisement. As intended, the majority of participants chose the MP3 advertisement. However, if participants chose the digital camera advertisement, participants were informed that the camera advertisement was not available and instead watched the MP3 advertisement. These participants were then excluded from the study's analysis because the inability to watch an advertisement they chose would influence their attention toward the MP3 advertisement itself. After watching the advertisement, participants reported the amount of attention they paid to the advertisement which constituted the dependent variable. Participants then watched another clip of either a choir performance or another Celebrity Jeopardy skit. Like the opening part of this study, participants were instructed to 
complete measures concerning this video clip after they finished watching it. After completing these measures, participants indicated their sex in a demographic section of the survey. Finally, participants were thanked and debriefed after these measures were completed.

\section{Results}

To analyze the effects of advertisement choice on participants' attention, the authors conducted a factorial ANOVA where advertisement choice and participant sex were the factors. Self-reported attention towards the advertisement was the dependent variable. Before the factorial ANOVA was conducted, the data was first checked for statistical normality [41]. Since advertisement choice and participant sex were both nominal variables, statistical normality was checked for each of the four factorial conditions (male-choice, male-no choice, female-choice, and female-no choice). Statistical normality was checked by identifying the presence of missing data, univariate outliers, and skewness of the attention Likert item. The presence of univariate outliers was defined as any attention rating greater than $|3.29|$ standard deviations away from the factorial condition mean. Attention skewness was defined as any condition distribution with a skewness statistic greater than |3.2| standard errors. There were no instances of missing data or statistical violations in any of the four factorial conditions. Thus all 158 participants were used in the factorial ANOVA.

Results from the ANOVA showed no main effect of advertisement choice on attention, $F(1,154)=1.12, p=.29, \eta_{p}^{2}=.007$, indicating that amount of attention paid to the advertisement for male and female viewers was not significantly different between the choice and no choice conditions. Such a finding disconfirms the first hypothesis of this study. There was also no main effect of participant sex, $F(1,154)=0.13, p=.72, \eta^{2}=.001$, on participants' attention indicating similar amounts of attention towards the advertisement between male and 
female participants in both choice conditions. There was, however, a significant interaction between advertisement choice and participant sex on self rated attention, $F(1,154)=5.55, p=$ $.02, \eta_{p}^{2}=.035$. An analysis of simple effects showed that advertisement choice did not have a significant effect on male participants' attention, $F(1,76)=1.00, p=.32, \eta_{p}^{2}=.013$, indicating no difference in the amount attention paid towards the advertisement between the choice conditions [no choice: $M=5.52, S D=1.47$ : choice: $M=5.21, S D=1.27$ ] for males. In contrast, advertisement choice did have a significant effect on female participants' attention, $F(1,78)=$ $4.99, p=.03, \eta^{2}{ }_{p}=.060$, indicating significantly higher amounts of attention paid towards the advertisement for the choice condition than no choice condition [no choice: $M=5.04, S D=1.63$ : choice $M=5.87, S D=1.18$ ] for females, showing support for the second hypothesis.

\section{Discussion}

The results of the study provide no support for the first hypothesis but support for the second. Female viewers did attend to the advertisement more when given a choice over which advertisement to be exposed to, however, male viewers showed no effect. The lack of an effect of advertisement choice on males may not be that surprising the previously noted differences between the sexes in various consumer and advertising literatures. It is possible that men generally see advertisement choice as an unimportant process because the end result concerns an advertisement (which relates to shopping) that they do not care to see. At worst, it is possible that men may have reacted (by reducing their attention) against the advertisement to a small degree if they perceived the choice of content as a prime to upcoming influence of the advertisement itself [16]. This more intriguing possibility actually has some relevance to certain advertising models such as Ducoffe's [13] advertising value model. 
Ducoffe suggests that individuals determine an advertisement's value through three factors: entertainment, informativeness, and irritation. While increases in the first two factors lead to higher advertisement value, the opposite is true for irritation. Sun, Lim, Jiang, Peng, and Chen [40] showed that females typically place more weight on the entertainment value of an advertisement while males typically place more weight on an advertisement's information value. With sex differences present for the entertainment and informativeness factors, one untested question is whether there are sex differences for irritation. If so, one application of this study for Ducoffe's model is to assess whether or not advertisement choice affects the irritation dimension differently for men and women. Such a difference would indicate a possible mechanism to explain the effect of advertisement choice on individuals' attention. However, this possibility of course needs further examination.

The implications of this study suggest that advertisement choice as a means of providing control of advertisement content to viewers should be limited to female individuals. The lack of any choice manipulation on males suggests that providing an option will probably not have any subsequent benefit for the advertiser. Females on the other hand seem much more receptive to choice as an aspect of the advertisement experience, and thus this method should be used selectively to reflect that difference. From the authors' perspective, there are three main ways to use this advertisement choice selectively. The first is to provide choice of advertisement content on websites that females visit. Such websites can be visited predominately by females or they can be visited by a large amount of individuals from both sexes. As long as the website is visited by a large number of females, this advertising method should provide benefits for the female viewers and advertisers. A second yet similar use of this method is to provide advertisement choice for streamed web content that is watched predominately by females. For a website such 
as hulu.com, this technique would seem to be effective for shows/movies that are viewed predominately by women. A third use of this method could be to provide advertisement choice options that are themselves tailored more toward female viewers. Such examples would include products that are used by a large number of women (regardless of whether products are exclusively used by women or not). Since men do not seem to be affected by this technique, the use of such options should not matter since they would likely avoid the advertisement regardless. For females, however, giving such options would allow them to selectively choose advertisement exposure and thus attend more to the selected item which is one goal advertisers seek.

Regardless of the way in which this methodology is used, the results of this study show that female individuals will at least be more inclined to watch advertisement content when they are allowed to choose which content to be exposed to. This in turn makes subsequent persuasion more likely.

\section{Conclusions}

The differential effect of advertisement choice between males and females is an interesting phenomenon that deserves more investigation. With the increase of consumer interaction within the web advertising medium, further study of the effects of new approaches like advertisement choice on consumers' cognitive as well as attitudinal outcomes appears warranted. Such investigation(s) can be obtained by using different measures of attention, different dependent variables, and different moderating variables. Since this study utilized a self-report measure of attention, one line of research could assess the external validity of these findings to other measures of attention such as eye tracking measures. In addition, other dependent variables related to the persuasion literature such as ad, product, and brand attitudes can be included in subsequent work to investigate the potential effect of advertisement choice. 
Lastly, one other line of research can explore how different moderating variables such as other individual difference or contextual factors can moderate the advertisement choice-attention relationship. In the persuasion literature such individual difference variables can include need for cognition [5] or self-monitoring [39] while such contextual factors can include the number of choice options themselves. With a multitude of investigations possible, the study of advertisement choice on various persuasion constructs appears to be a future line of research which could not only progress persuasion theories, but it also has the possibility to benefit advertisers and web users themselves in an applied manner. 


\section{References}

[1] D.S. Ackerman, B.L. Gross, How many choices are good? Measurement of the effects of course choice on perceptions of a marketing option, Journal of Marketing Education 28 (2006) 69-80.

[2] P. Alreck, R.B. Settle, Gender effects on Internet, catalogue and store shopping, Journal of Database Marketing 9 (2002) 150-162.

[3] D.J. Anschutz, R.C.M.E. Engels, C.S. van der Zwaluw, T. Van Strien, Sex differences in young adults' snack food intake after food commercial exposure, Appetite 56 (2011) 255-260.

[4] J.W. Brehm, Postdecision changes in the desirability of alternatives, Journal of Abnormal and Social Psychology 52 (1956) 384-389.

[5] J.T. Cacioppo, R.E. Petty, The need for cognition, Journal of Personality and Social Psychology 42 (1982) 116-131.

[6] J.T. Cacioppo, R.E. Petty, C.E. Kao, R. Rodriguez, Central and peripheral routes to persuasion: An individual difference perspective, Journal of Personality and Social Psychology 51 (1986) 1032-1043.

[7] J.T. Cacioppo, R.E. Petty, K.J. Morris, Effects of need for cognition on message evaluation, recall, and persuasion, Journal of Personality and Social Psychology 45 (1983) 805-818.

[8] C. Campbell, Shopping, pleasure and the sex war, in: P. Falk, C. Campbell (Eds.), The Shopping Experience, Sage, London, 1997, pp. 166-176.

[9] A. Chattopadhyay, P. Nedungadi, Does attitude toward the ad endure? The moderating effects of attention and delay, Journal of Consumer Research 19 (1992) 26-33.

[10] C. Cho, J. Lee, M. Tharp, Different forced-exposure levels to banner advertisements, 
Journal of Advertising Research 41 (2001) 45-56.

[11] J.L. Cotton, R.A. Hieser, Selective exposure to information and cognitive dissonance, Journal of Research in Personality 14 (1980) 518-527.

[12] R.R. Dholakia, Going shopping: Key determinants of shopping behaviours and motivations, International Journal of Retail and Distribution 27 (1999) 154-165.

[13] R.H. Ducoffe, Advertising value and advertising on the Web, Journal of Advertising Research 36 (1996) 21-35.

[14] A.H. Eagly, S. Chaiken, The Psychology of Attitudes, Harcourt Brace, Fort Worth, 1993.

[15] A.H. Eagly, S. Chaiken, Attitude research in the 21st century: The current state of knowledge, in: D. Albarracín, B.T. Johnson, M.P. Zanna (Eds.), The Handbook of Attitudes, Erlbaum, Mahwah, 2005, pp. 743-767.

[16] A.H. Eagly, W. Wood, L. Fishbaugh, Sex differences in conformity: Surveillance by the group as a determinant of male nonconformity, Journal of Personality and Social Psychology 40 (1981) 384-394.

[17] L. Festinger, A Theory of Cognitive Dissonance, Stanford University Press, Stanford, 1957.

[18] J.L. Freedman, J.D. Steinbruner, Perceived choice and resistance to persuasion, Journal of Abnormal and Social Psychology 68 (1964) 678-681.

[19] J. Friedrich, D. Fetherstonhaugh, S. Casey, D. Gallagher, Argument integration and attitude change: Suppression effects in the integration of one-sided arguments that vary in persuasiveness, Personality and Social Psychology Bulletin 22 (1996) 179-191.

[20] D. Frey, R.A. Wicklund, A clarification of selective exposure: The impact of choice, Journal of Experimental Social Psychology 14 (1978) 132-139.

[21] K. Goodrich, Anarchy of effects? Exploring attention to online advertising and multiple 
outcomes, Psychology \& Marketing 28 (2011) 417-440.

[22] W. Hart, D. Albarracín, A.H. Eagly, I. Brechan, M.J. Lindberg, L. Merrill, Feeling validated versus being correct: A meta-analysis of selective exposure to information, Psychological Bulletin 135 (2009) 555-588.

[23] C.P. Haugtvedt, R.E. Petty, J.T. Cacioppo, Need for cognition and advertising: Understanding the role of personality variables in consumer behavior, Journal of Consumer Psychology 1 (1992) 239-260.

[24] C.I. Hovland, I.L. Janis, H.H. Kelley, Communication and Persuasion: Psychological Studies of Opinion Change, Yale University Press, New Haven, 1953.

[25] E. Jonas, S. Schulz-Hardt, D. Frey, N. Thelen, Confirmation bias in sequential information search after preliminary decisions: An expansion of dissonance theoretical research on selective exposure to information, Journal of Personality and Social Psychology 80 (2001) 557-571.

[26] W.J. McGuire, Personality and susceptibility to social influence, in: E.F. Borgatta, W.W. Lambert (Eds.), Handbook of Personality Theory and Research, Rand McNally, Chicago, 1968, pp. 1130-1187.

[27] D. Miller, A Theory of Shopping, Blackwell Publishing, Oxford, 1998.

[28] D.J. Moore, Emotion as a mediator of the influence of gender on advertising effectiveness: Gender differences in online self-reports, Basic and Applied Social Psychology 29 (2007) 203-211.

[29] S. Okazaki, Expoloring gender effects in a mobile advertising context: On the evaluation of trust, attitudes, and recall, Sex Roles 57 (2007) 897-908.

[30] R.E. Petty, J.T. Cacioppo, Issue-involvement can increase or decrease persuasion by 
enhancing message-relevant cognitive responses, Journal of Personality and Social Psychology 37 (1979) 1915-1926.

[31] R.E. Petty, J.T. Cacioppo, The effects of involvement on responses to argument quantity and quality: Central and peripheral routes to persuasion, Journal of Personality and Social Psychology 46 (1984) 69-81.

[32] R.E. Petty, J.T. Cacioppo, The elaboration likelihood model of persuasion, in: L. Berkowitz (Ed.), Advances in Experimental Social Psychology, Academic Press, New York, 1986, pp. 123-205.

[33] R.E. Petty, J.T. Cacioppo, Attitudes and Persuasion: Classic and Contemporary Approaches, Westview Press, Boulder, 1996.

[34] R.E. Petty, J.T. Cacioppo, M. Heesacker, The use of rhetorical questions in persuasion: A cognitive response analysis, Journal of Personality and Social Psychology 40 (1981) 432 440.

[35] R.E. Petty, J.T. Cacioppo, D. Schumann, Central and peripheral routes to advertising effectiveness: The moderating role of involvement, Journal of Consumer Research 10 (1983) 135-146.

[36] S. Putrevu, Consumer responses toward sexual and nonsexual appeals: The influence of involvement, need for cognition (NFC), and gender, Journal of Advertising, 37 (2008) 57-69.

[37] A.E. Schlosser, S. Shavitt, The effect of perceived message choice on persuasion, Journal of Consumer Psychology 19 (2009) 290-301.

[38] B. Schwartz, The Paradox of Choice, HarperCollins, New York, 2004.

[39] M. Snyder, Self-monitoring of expressive behavior, Journal of Personality and Social 
Psychology 30 (1974) 526-537.

[40] Y. Sun, K.H. Lim, C. Jiang, J.Z. Peng, X. Chen, Do males and females think in the same way? An empirical investigation on the gender differences in Web advertising evaluation, Computers in Human Behavior 26 (2010) 1614-1624.

[41] B.G. Tabachnick, L.S. Fidell, Using Multivariate Statistics, fifth ed., Pearson, Boston, 2007.

[42] J.M. Wolburg, J. Pokrywczynski, A psychographic analysis of generation y college students, Journal of Advertising Research 41 (2001) 33-52.

[43] Y. Zhang, R. Buda, Moderating effects of need for cognition on responses to positively versus negatively framed advertising messages, Journal of Advertising 28 (1999) 1-15. 